\title{
A IMPORTÂNCIA DA EDUCAÇÃO PARA OS PORTADORES DE NECESSIDADES ESPECIAIS ${ }^{1}$
}

Mário Lúcio de Lima Nogueira*

\section{RESUMO}

Este trabalho pretende trazer à reflexão o sentido que a Educação tem para os portadores de necessidades especiais tendo como foco principal a formação do caráter destes indivíduos, bem como a formação de atitudes e a compreensão de mundo e de sua inserção nele. Estas reflexões nos levam a entender a Educação Especial como sendo a busca de práticas pedagógicas que respondam à diversidade do alunado no contexto da escola para todos, oferecendo respostas educacionais centradas no processo de construção da cidadania de todos os alunos, especiais ou não.

PALAVRAS-CHAVE: Educação inclusiva. Educação. Formação de professores.

\section{ABSTRACT}

This paper aims to promote a reflection about the meaning education has for those who carry special necessities. We will be focusing on the formation of the character of these individuals, as well as the formation of attitudes, the comprehension of the world

1 O termo portador de necessidades especiais é aqui referido a todas aquelas crianças ou jovens cujas necessidades originam-se em função de deficiências ou dificuldades de aprendizagem, conforme o texto final da Declaração de Salamanca (UNESCO. Declaração de Salamanca e linhas de ação sobre necessidades educacionais especiais. Brasília: CORDE, 1994, p.17).

* Mestre em Educação pela Universidade do Estado do Rio de Janeiro. 
around them and their insertion in it. These reflections are to make us see special education as a search for pedagogical practices which can consider how different students are in the context of a school for everyone, so that it can bring educational responses based on the construction process of citizenship for every student, no matter how special or normal each one happens to be.

KEYWORDS: Inclusive education. Education. Teacher formation.

Ao buscarmos o sentido da educação para os portadores de necessidades especiais, nos deparamos com a necessidade de pensar a própria educação, pois "de todas as interrogações e de todos os questionamentos, sem dúvida o mais essencial, sempre implicitamente presente aos demais, diz respeito ao próprio sentido da educação" (VALLE, 2000, p. 36).

Isto nos põe, indubitavelmente, frente à exigência de compreender e avaliar valores, saberes e práticas educacionais cotidianas, segundo um pensar auto-reflexivo e consciente de seu caráter e suas dimensões históricas. Esta prática educacional, que resiste à imposição de uma normalidade totalizante e excludente, alcança seu desenvolvimento mais afirmativo no momento de pensar sobre as condições e possibilidades de emergência de outros valores, outras idéias e práticas diferentes das atuais.

O advir é uma possibilidade [abstrata], mas não uma fatalidade para todo ser humano: ele é criação histórica e criação cuja história podemos acompanhar. Esse sujeito, a subjetividade humana, é caracterizado pela reflexividade [que não se pode confundir como simples "pensamento"] e pela vontade ou capacidade de ação deliberada, no sentido forte desse termo (CASTORIADIS, 1987, p. 207).

O espaço educativo está hoje passando por uma condição de indefinição, caracterizada pelo descompasso entre o reconhecimento das novas tecnologias e de suas implicações em 
todo o processo educativo e a convicção de que o passado - o já experimentado, o já legitimado - pode ainda postular referências à ação do presente. O dilema apresenta-se na (im)possibilidade de conciliar o passado e o presente. Nos diz Castoriadis (1982, p. 46) que "não se pode tirar o homem daquilo que o fez tal como ele é, nem daquilo que, tal como ele é, ele faz. Mas não se pode tampouco reduzi-lo a isso".

As diversas solicitações feitas à comunidade escolar, oriundas dos diferentes espaços institucionais, exigindo mudanças, avaliações, novas posturas, novos objetivos, e/ ou novos resultados, refletem a fragmentação e a multiplicidade entre os discursos e as reais ações sociais levadas a efeito. $\mathrm{O}$ caráter instituinte da prática escolar vem sendo anulado pelos discursos e idéias salvadoras produzidas pelas instituições sociais responsáveis. Instaura-se um impedimento ou, pelo menos, uma inibição para que se construa um projeto educacional à luz das construções dos próprios atores do sistema - a comunidade escolar. Nestas críticas e discussões educacionais, perdem-se de vista, na maior parte das vezes, as características de temporalidade e de flexibilidade próprias do processo educativo. Particularmente, quando se fala de portadores de necessidades especiais, há que se acrescentar a boa ou má vontade política dos governantes que, muitas vezes, desconhecem e banalizam as ações educacionais com relação a estes alunos. Como alcançar um sentido de educação, quando existe toda uma trajetória de desconstrução do papel criador, decorrente da conciliação entre possível e necessário?

Contemporaneamente, o saber foi atingido pelo critério da "performatividade". A pergunta "que tipo de homem formar?" perdeu seu sentido e, em seu lugar, surgem outras, tais como: "quem transmite?"; “o que transmite?"; “com que suporte?"; "de que forma?"; "com que efeito?". A transmissão de saberes já não surge destinada a formar indivíduos capazes de guiar uma nação na sua emancipação. Antes, fornece ao sistema pessoas com a mera capacidade de assegurar, convenientemente, o seu papel nos lugares pragmáticos que as instituições necessitam. Esta concepção de educação, como um bem de investimento, nos faz lembrar das 
teorias de capital humano, pouco ou quase nada favoráveis aos portadores de necessidades especiais que, em virtude dos preconceitos existentes, são considerados incapazes de aprender e de serem inseridos no mercado de trabalho. No entanto, como diz Castoriadis (1987), o "espantoso no humano não é que ele aprenda, mas que não aprenda" (p. 218).

As instituições educacionais têm sido, historicamente, percebidas como instrumentos de mudança com vistas não só para a formação de uma nova ordem social mais justa, mas também para a manutenção da ordem, da dominação e conformismo. No entanto, para que isto realmente aconteça, a educação não deveria receber a incumbência de promover uma racionalidade que pensasse nos verdadeiros fins desta sociedade, hoje ainda injusta, ao invés de transmitir, como tem sido norma, uma racionalidade meramente técnica ou instrumental? Neste contexto, a nós educadores importa recriar possíveis sentidos para um filosofar comprometido com a problematização dos princípios e fins que movem as práticas e os saberes pedagógicos, ou seja, devemos nos preocupar em inserir estas questões como uma força que colabore para melhorar nossa realidade educativa.

As teorias clássicas de educação de Kant (1996) e Rousseau (1983) - que se nos apresentam, ainda hoje, como uma inquietante realidade - buscaram responder a questões vitais da sociedade, tais como: de que forma se pode retirar o indivíduo de um contexto de submissão para colocá-lo em um contexto de liberdade e autonomia? - ou, como pode ser concebida uma ação pedagógica, que também seja social e que não possua um caráter objetivante e instrumental?

Como nos diz Kant (1996, p. 28) “[...], não é suficiente treinar as crianças; urge que aprendam a pensar", e isto não deve ser diferente para os portadores de necessidades especiais. Não se trata, no entanto, de criar um sujeito epistêmico formal, um robô inteligente, mas sim de desenvolver esta capacidade de pensar dos indivíduos que possuem saberes advindos da experiência própria, que estão condicionados por culturas particulares e que querem ascender a conhecimentos mais universais, como os conhecimentos científicos sem, no entanto, supervalorizar o cognitivismo. 
Perguntaríamos nós, então: o que transmitir a estes nossos alunos, nesta concepção de saber? Como legitimar a educação que vise a se constituir em um processo de formação?

Estaríamos, então, diante de um paradoxo que faz com que a crítica ao dogmatismo que condenamos, especialmente na herança filosófica, e em nome de um conhecimento que se dá como construção, nos obrigue a renunciar a qualquer responsabilidade na tarefa de definição dos limites e das exigências deste mesmo processo de construção, e, em nome, exatamente, da relatividade e da precariedade de nossas certezas? (VALLE, 2000, p. 34).

Quando pensamos em educação, pensamos na formação do caráter dos indivíduos, na formação de atitudes, na compreensão de mundo e de sua inserção nele. Pensamos que é possível desenvolver-lhes o senso crítico e a autonomia. Pensamos, também que, juntamente com a informação há, ainda, um componente de juízo e de discernimento que se apresenta no processo educacional e que nos capacita a reconhecer, interpretar e decidir sobre que regras devemos aplicar no contexto social em que vivemos, bem como descobrir que ações são permitidas por estas regras e quais devemos executar, dadas as circunstâncias que se nos apresentam no momento de aplicá-las.

Deve haver regras para tudo aquilo que pode cultivar o entendimento. É também muito útil abstraí-las, para que o entendimento proceda não apenas mecanicamente, mas tenha consciência da regra que segue (KANT, 1996, p. 71).

Espera-se que este processo educacional seja antecedido por criteriosa avaliação e que as informações obtidas permitam aos agentes escolares decidirem sobre as intervenções necessárias para garantir a aprendizagem de todos os educandos, inclusive os portadores de necessidades especiais. Desta forma, talvez a Educação Especial possa ser reconceitualizada, deixando de ser 
entendida como a educação dirigida a um grupo de alunos chamados de especiais apenas por suas características diferenciadas ou suas deficiências pessoais. ${ }^{2}$

Estas questões possuem um valor inestimável porque vivemos em uma sociedade cada vez mais tecnológica que, apresentando novas características e novas exigências, nos obriga, cada vez mais, a perguntar qual o papel destinado à educação na construção da autonomia e da liberdade de todos os indivíduos, inclusive os portadores de necessidades especiais. A educação, ao nosso ver - e como nunca deveria deixar de ser - permaneceria em condições de ajudar a construir o projeto de emancipação social. Um sujeito capaz de construir suas próprias relações com as situações do cotidiano é alguém que, de alguma maneira, está construindo sua autonomia. Em síntese, a educação deveria ser entendida como o eixo que possibilita que todos os indivíduos possam e devam se apropriar do saber, do saber fazer, do saber pensar e do saber que sabem.

Dentro deste complexo processo educacional somam-se, ainda, os novos conceitos internacionais sobre Educação Especial que, referendados pelas leis brasileiras, levam-nos a considerar a Educação Inclusiva ${ }^{3}$ como uma das melhores formas de acolher esta clientela de alunos especiais que, muito mais que apenas atendimento, precisam de educação, pois como nos dizia Kant (1996, p. 15), “o homem não pode tornar-se um homem senão pela educação. Ele é aquilo que a educação dele faz".

Também não é nova a idéia de que apenas na interação com seus pares que o homem pode pensar a aprendizagem como processo de desenvolvimento do pensamento que o possibilitará

2 A Educação Especial é aqui referida como um conjunto de meios e materiais postos à disposição do sistema educativo, para que possa responder satisfatoriamente às necessidades particulares de todos os alunos, portadores ou não de necessidades especiais.

3 Em decorrência de debates realizados durante as diversas conferências sobre educação, na última década, e reforçado pela Declaração de Salamanca (1994), pode-se dizer que já existe um consenso emergente de que crianças e jovens com necessidades educacionais especiais preferencialmente devam ser incluídos em escolas comuns, tal como a maioria das crianças.

Educ. e Filos., Uberlândia, v. 20, n. 40, p. 159-172, jul./dez. 2006. 
saber como obter e selecionar o conhecimento necessário para interagir com a realidade e suas transformações. Já nas palavras de Kant (1996, p. 24), começamos a entender que

A árvore que permanece isolada no meio do campo não cresce direito e expande longos galhos; pelo contrário, aquela que cresce no meio de uma floresta, cresce ereta por causa da resistência que lhe opõem as outras árvores e, assim, busca por cima o ar e o sol.

Em convivência, os indivíduos tomam consciência de si, de seus iguais e do todo social. Seguind o o mesmo raciocínio, acreditase que, para que os portadores de necessidades especiais possam desenvolver-se global e harmoniosamente, precisam estar na companhia de pessoas que lhes sirvam de exemplo e facilitem seu processo de integração social. Entretanto, o que vemos na prática é a sua segregação sob o argumento de que, desta forma, poderão ter um atendimento melhor. Com esta atitude, o que se consegue, na verdade, é aumentar as desigualdades. Para Rousseau (1983, p. 264),

A educação não só estabelece diferença entre os espíritos cultos e os que não o são, como também aumenta a que existe entre os primeiros na proporção da cultura, [...] e quanto aumenta a desigualdade natural da espécie humana por causa da desigualdade de instituições.

\section{O professor no contexto da Educação Inclusiva}

Estaremos nós, educadores, preparados para sermos parte integrante e condutores neste processo de inclusão educacional? Em outras palavras, estamos capacitados para receber estes alunos, portadores de necessidades especiais, em nossas salas de aula e de trabalhar atentos às suas especificidades?

Para podermos atender à diversidade, faz-se mister que tenhamos, em nosso processo de formação, um currículo que contemple um conjunto de medidas que, compatíveis com as 
necessidades dos alunos, nos permitam encontrar respostas educacionais possíveis e integradas com as especificidades de cada um. Há uma necessidade premente de que nós, educadores, façamos reflexões acerca de nossa formação e de nossa desinformação no que diz respeito às necessidades especiais emergentes em nossas salas de aula. Parece ser evidente que, todos, precisamos estar convenientemente preparados para que possamos desenvolver a capacidade de nos interrogarmos sobre quem são estes alunos e quais são, para eles, as melhores estratégias educacionais dentro de um contexto de Educação Inclusiva.

Evidentemente, falamos de possibilidades do ser humano; não dizemos que elas são sempre realizadas, na maior parte do tempo, automaticamente, etc. sabemos pertinentemente que o contrário é verdadeiro; mas sabemos também que essas possibilidades são atualizáveis, que foram atualizadas por certas sociedades e certos seres humanos, que pensar, psicanalisar, dizer o que dizemos pressupõe esta atualização (CASTORIADIS, 1987, p. 233).

Se estas questões tiverem, de nossa parte, um encaminhamento positivo, e estiverem aliadas a uma competente vontade políticoeducacional, o processo inclusivo da educação tenderá a se concretizar. No entanto, a experiência nos tem mostrado o contrário. Nossa formação básica nada, ou quase nada nos preparou para questionar sobre a Educação Especial e, na maioria das vezes, o que sabemos sobre ela é baseado em preconceitos. Como nos diz Arendt (1998, p. 29),

Os preconceitos não são idiossincrasias pessoais que, apesar da impossibilidade permanente de sua indemonstrabilidade, sempre remontam a uma experiência pessoal dentro da qual persiste a evidência de percepções sensoriais.

Em relação aos portadores de necessidades especiais, estes sentimentos concretizam-se, também, no próprio indivíduo, pois 
o que o torna diferente de seus pares também o leva a sofrer restrições. Em virtude disto, sua auto-imagem fica prejudicada, sobrevindo-lhe o sentimento de que vale menos que os "normais".

E, prossegue Arendt (1998, p. 30), “[...] não existe nenhuma estrutura social que não se baseie mais ou menos em preconceitos, através dos quais certos tipos de homens são permitidos e outros excluídos".

Como resolver esta situação? Esta é uma das questões que vêm preocupando todos os que acreditam que a inclusão dos portadores de necessidades especiais nas salas de aula de ensino regular seja uma solução melhor do que a que vinha sendo adotada até agora, ou seja, a de discriminá-los em salas ou instituições especiais.

Ao olharmos a história, podemos verificar que todas as sociedades, ao sentiram-se pressionadas por qualquer tipo de necessidade buscaram desenvolver, em menor ou maior grau, conhecimentos e procedimentos que lhes garantissem capacidade de intervenção na realidade em que viviam e, conseqüentemente, solucionar suas demandas. Para Rosseau (s.d., p. 65), uma das qualidades que distingue o homem do animal é "a sua faculdade de aperfeiçoar-se, faculdade que, com o auxilio das circunstâncias, desenvolve sucessivamente todas as outras e se encontra entre nós, tanto na espécie quanto no indivíduo".

\section{A tecnologia como meio na interrogação dos professores para a educação especial}

No mundo contemporâneo, vemos a tecnologia invadindo todos os domínios da atividade humana na procura de melhorar a qualidade de vida do homem e, como via social, permitindo diminuir ou até mesmo eliminar as desigualdades em alguns casos, enquanto que em outros tende a aumentar estas diferenças.

Vivemos em uma época tecnocrática, de adoração ao ídolo tecnologia. A educação não é uma exceção neste contexto. Porém, a necessidade de incorporar as novas tecnologias às escolas, tanto no ensino, quanto na pesquisa, nos leva a perguntar: Quais são os pressupostos, em termos de concepções de ser humano, que se 
afirmam passíveis de utilizarem-se deste novo aparato tecnológico? Quais são as suas possíveis implicações? Para que tipo de pessoas e que tipo de relações interpessoais entre alunos e professores estas tecnologias podem contribuir? Importa-nos, ainda, questionar sobre o uso que estamos fazendo desta tecnologia, seus fins e seus valores bem como suas implicações e contribuições na formação do sujeito.

Paradoxalmente, apesar do impressionante avanço nas ciências e na tecnologia, o progresso não passa de fantasia para a imensa maioria de seres humanos do planeta e a normalidade imperante nos meios sociais está longe de responder pelas demandas de justiça e eqüidade. A contradição da civilização tecnológica está em sua capacidade de gerar riqueza sem, no entanto, distribuí-la ao conjunto da humanidade.

Não há dúvida, no entanto, que a tecnologia vem exercendo profundas influências no modo de ser e de pensar da cada um de nós, além de criar novas formas de organizar a sociedade tecnológica que pode ser entendida como um sistema de organização social baseado no progresso do conhecimento, da informação e da técnica.

A formação de uma nova consciência social é, tradicionalmente, um lento processo de elaboração cultural que depende do desenvolvimento da capacidade crítica dos indivíduos ao compartilharem condições de vida semelhante. É um fenômeno de classes sociais em luta pela sobrevivência material e pelas idéias que defendem. A consciência comum que passa, assim, a ser desenvolvida, depende da cultura e da educação recebidas.

Se os meios tecnológicos estão, hoje, cumprindo esta função socializadora com uma rapidez vertiginosa, é lógico perguntarmos: Como responder aos novos desafios por eles gerados? Como discutílos em um plano estritamente acadêmico? Como podem eles colaborar com os processos educacionais? Como podem servir à educação especial?

Estes desafios podem ser próprios das ciências sociais, mas vinculam-se fortemente com a educação, não nos permitindo esquecer de aportes pedagógicos, psicológicos e epistêmicos em que o papel do discurso pedagógico será o de sintetizar estes aportes. 


\section{A Educação Inclusiva como sentido de construção social}

Como já vimos, um dos grandes problemas enfrentados pela Educação Especial é a de que o aluno das classes especiais pouco ou quase nada aprende e isto se deve, também, aos professores que sentem-se despreparados ou mau assistidos neste seu trabalho. Vem-nos, imediatamente, a pergunta: Se os professores que se encontram em salas especiais sentem-se assim, o que acontece com o professor do ensino regular que recebe alunos portadores de necessidades especiais em sua sala de aula? Como podemos resolver ou, ao menos, minorar esta situação em que se destaca o professor, que dá qualidade e orientação à educação?

Esta situação não passou despercebida pelas autoridades. A Portaria 1.793/94 do MEC, dentre outros exemplos, recomenda que, além de estágios com alunos que apresentam necessidades especiais, os cursos de formação de professores incluam em seus currículos disciplinas referentes ao atendimento de pessoas portadoras de necessidades especiais. No entanto, até que esta e outras medidas surtam efeito, é necessário que tenhamos outros meios de enfrentar as dificuldades adicionais que uma Educação Inclusiva certamente trará a todos os profissionais de educação, particularmente àqueles que já se encontram nas salas de aula em todo o país.

As estratégias de educação à distância talvez possam representar um recurso valioso no enfrentamento desta dificuldade. Para muitos professores esta será, talvez, a única oportunidade de atualizar conhecimentos e de debater com outros docentes quais as melhores formas de atender, educacionalmente, a alunos com necessidades especiais.

Neste momento, em que a rapidez pela busca de soluções para enfrentar as dificuldades da Educação Inclusiva torna-se uma realidade, acredito que a realização de cursos à distância, com a utilização da tecnologia informática, destinado à capacitação de professores do ensino regular para atuarem com portadores de necessidades especiais, pode vir a ser uma experiência que não devemos desprezar a priori, pois nas palavras de Kant (1996, p. 30), 
[...] crê-se geralmente que não é preciso fazer experiências em assuntos educacionais e que se pode julgar unicamente com a razão se uma coisa é boa ou má. Vê-se, pois que, sendo neste assunto necessária a experiência, nenhuma geração pode criar um modelo completo de educação.

Enfrentamos, sempre, a necessidade de aclarar o que significa formar um indivíduo em termos desta capacidade básica que lhe permita colocar-se ante a realidade em que vive, pensar esta realidade e atuar frente a ela, mesmo sabendo que o "mundo acessível à subjetividade humana, não é dado de uma vez para sempre, ele é ao mesmo tempo extensível e modificável (para "fora" e para "dentro")" (CASTORIADIS, 1987, p. 237).

O conhecimento que construímos é, também, construção de sentido. O conhecimento está vinculado a construções sociais determinadas e, no caso da educação, vinculado a um discurso pedagógico que se traduz em ações cujo sentido não é teórico, mas sim prático, isto é, um sentido dentro do qual constrói-se o conhecimento. Desta forma, se o conhecimento constitui-se em sentido - o conhecimento que construímos em âmbito geral das ciências sociais - temos que inserí-lo em um marco de opções de construção social. O conhecimento, em si mesmo, não é uma opção, mas constitui-se em um instrumento que permite ou não certas construções sociais. Se quisermos que o conhecimento sirva para potencializar realidades, por intermédio do processo de formação, teremos que atentar para o problema das ações.

Apesar da emergência de valores próprios à sociedade capitalista, tais como consumismo, transgressão ao meio ambiente e o individualismo, o homem moderno busca, ainda e sempre, um sentido para sua existência em que se insere a justiça, a solidariedade e a ética, e isto é verdade tanto para o homem comum como para o portador de necessidades especiais.

A educação é um projeto em permanente construção, a partir de nossa capacidade de dar uma (re)significação ao passado à luz do presente e do futuro que se anuncia. Perguntar, hoje, qual o sentido de educação, particularmente para os portadores de 
necessidades especiais, exigirá-nos uma compreensão desses novos tempos e uma capacidade de não anularmos, mas de convivermos com o fragmentário na perspectiva de produzir a unidade - a nova unidade, pois "[...] a elucidação daquilo que se é, de sua autoalteração implica na consciência de que o que se é não resulta de uma fatalidade, mas sempre, também, de uma escolha" (VALLE, 2000, p. 47). Há, portanto, criações e deliberações que não são apenas individuais, mas coletivas; não somente éticas, mas também políticas.

Ao pensarmos sobre o sentido da educação, incluindo-se neste pensar o sentido da educação para os portadores de necessidades especiais, podemos traduzir a Educação Especial como a busca por práticas pedagógicas que respondam à diversidade do alunado no contexto da escola para todos, oferecendo respostas educacionais centradas no processo de construção da cidadania de todos os alunos, especiais ou não.

Mas, apropriando-nos do que nos fala Castoriadis (1982, p. 37) sobre a ciência, também em educação, não podemos nos esquecer que,

[...] as soluções não têm o sentido que elas têm em outros domínios; não são soluções corretas, condicionalmente categóricas, podendo, portanto, ser ultrapassadas ou anuladas se modificarmos o conjunto de condições que as sustentam; são soluções enquanto permitem pensar o que pode ser reduzido a um conjunto definido de condições.

E, dentro deste contexto, à medida que os conceitos de igualdade, liberdade e justiça se expandem, os próprios portadores de necessidades especiais evoluem de uma situação de passividade para uma outra de maior empenho, na busca de solução para seus problemas concretos. Este processo vem, cada vez mais, apontando para o sentido da igualdade de oportunidades, surgindo, então, um princípio, inicialmente chamado de "valorização" e depois de "normalização" que defende que a educação, a saúde, a habitação, o emprego, o lazer ou qualquer outro serviço para os portadores 
necessidades especiais devem considerar o valor do papel social a ser desempenhado por estes indivíduos, assegurando lhes, portanto, experiências "normais" em ambientes "normais".

\section{Referências}

ARENDT, H. O que é a política? Rio de Janeiro: Bertrandt Brasil, 1998.

CASTORIADIS, C. As encruzilhadas do labirinto I. Rio de Janeiro: Paz e Terra, 1982.

As encruzilhadas do labirinto III: o mundo fragmentado. Rio de Janeiro: Paz Terra, 1987.

KANT, I. Sobre a pedagogia. Piracicaba: UNIMEP, 1996.

ROUSSEAU, J.J. Discurso sobre a origem e os fundamentos da desigualdade entre os homens. In: Os Pensadores. São Paulo: Abril Cultural, p. 264-265, 1983.

VALLE L. A educação como enigma e como atividade práticopoética: implicações para o ensino da filosofia da educação. Revista Perspectiva, Santa Catarina, ano 18, n. 34, p. 33-48, jul./ dez. 2000.

UNESCO. Declaração de Salamanca e linhas de ação sobre necessidades educacionais especiais. Brasília: CORDE, 1994, p. 17. 